Article

\title{
Perceiving the Role of Communication Skills as a Bridge between the Perception of Spiritual Care and Acceptance of Evidence-based Nursing Practice-Empirical Model
}

\author{
Mariusz Panczyk *, Lucyna Iwanow, Szymon Musik, Dominik Wawrzuta, Joanna Gotlib and Mariusz Jaworski
}

Department of Education and Research of Health Sciences, Faculty of Health Sciences, Medical University of Warsaw, Zwirki I Wigury 81, 01580 Warsaw, Poland; mariusz.panczyk@wum.edu.pl (M.P.); lucyna.iwanow@wum.edu.pl (L.I.); szymon.musik@astrazeneca.com (S.M.); dominik.wawrzuta@wum.edu.pl (D.W.); joanna.gotlib@wum.edu.pl (J.G.); mariusz.jaworski@wum.edu.pl (M.J.)

* Correspondence: mariusz.panczyk@wum.edu.pl

\begin{abstract}
Decision-making using evidence-based practice (EBP) is generally universally accepted by nurses. Such acceptance may affect the personnel's behaviour towards patients, which is also demonstrated by taking into consideration the patient's preferences, including the patient's spiritual needs, in the care plan. The provision of such care requires the development of an attitude of approval and an adequate level of communicative competence, which will enable the actual implementation of the EBP. The purpose of our study was to assess the perception of spirituality and the nurse's role in providing spiritual care, as well as the perception of the significance of communication skills in the approval of EBP in professional practice. A multi-centre cross-section study was conducted on a population of 1176 participants (459 undergraduate (Bachelor programme, BP) and 717 postgraduate students (Master programme, MP)) from 10 medical universities in Poland. Three tools were used in the study to evaluate the participants' approach: Evidence-Based Practice Competence Questionnaire (EBP-COQ), The Spirituality and Spiritual Care Rating Scale (SSCRS), and Communication Skills Attitude Scale (CSAS). Structural equation modelling was used for the analysis. An analysis of structural equations revealed the presence of positive relationships of the attitude to spiritual care and the role of communicative competences with the approach to EBP regardless of the cohort. A significant difference was found related to the influence of age on the attitude toward learning communicative competences. The approval in this respect was observed to decrease with age in the MP group. Increasing approval of EBP requires strengthening the approach to activity-centred spiritual care, with the simultaneous development of a positive attitude towards learning communicative competences. The model reveals the need to integrate a humanistic approach with EBP, which can be achieved by planning different interventions in different groups of recipients: nurses, academic teachers and students.
\end{abstract}

Keywords: evidence-based practice; spiritual care; communication skills; path analysis

\section{Introduction}

According to the International Council of Nurses, evidence-based practice (EBP) in nursing is defined as "a problem solving approach to clinical decision making that incorporates a search for the best and latest evidence, clinical expertise and assessment, and patient preference values within a context of caring" [1]. It can be stated that EBP is based on decision-making, and is used to optimise patient outcomes, improve clinical practice, and ensure accountability in nursing [2]. The concept of EBP is characterised by a high level of acceptance by nursing students and working nurses [3], but there are still real barriers to its implementation in clinical practice [4].

As mentioned before, patient preference values and expectations are among the three EBP components that are most essential to therapeutic success. The roles of all three 
components are considered equal: scientific evidence, clinical expertise and assessment [5]. Good nursing care in EBP involves scientific evidence and knowledge derived from best practice being balanced with knowledge of the values and preferences of the individual patient [6].

The very first nursing models emphasised the patient's needs and expectations as an essential component of care. The model developed by Virginia Henderson, based strictly on Maslow's theory of needs, accentuates the therapeutic and caring role of the nurse, and refers to the patient's essential needs that the nurse is supposed to satisfy. This model applies not only to biological needs, but also to such higher needs as spirituality or contact with other humans [7]. The spiritual and humanistic dimension of care initiated by Henderson became the core of Jean Watson's model, which focused on the concepts of care and concern [8].

The important role of the nurse's communicative competence in making clinical decisions related to the EBP concept was also recognised and described in Hildegard Peplau's model [9]. It is not possible to understand the patient and identify their needs and expectations related to the therapeutic process without an excellent patient-nurse relation. Such a good relationship requires the nurse's positive approach (positive attitude) to learning communication skills. In the context of psychology, attitudes are a set of different variables (e.g., cognitive, emotional, etc.) that affect one's behaviour. Moreover, there is a strong relationship between the attitude and the behaviour. In other words, a change in the attitude entails a change in the behaviour [10].

A decision related to the direction of therapeutic and care activities can be made only when the professional's (nurse, physician) mindset is taken into consideration; however, it can also partly or fully consider the patient's opinions and wishes [5]. The active participation of the patient entails the need to include in the care situation their preferences, such as personal norms, values, characteristics, and wishes. They often also include spiritual needs, which the nurse must take care of to satisfy the patient's emotional needs. The provision of spiritual care by a nurse means that the nurse must employ a wide range of communication tools, without which the care cannot be provided effectively.

There are several publications devoted to nurses' perceptions of the role of communication skills in the context of EBP [5,11] and spiritual care [12]. The number of papers analysing the nurses' attitude towards these skills is limited [13]. More importantly, there are no studies analysing these issues together, as three interrelated aspects of nursing care, in one integrated model.

\subsection{Conceptual Framework}

The proposed theoretical model assumes that the provision of activity-centred spiritual care (ACSC) will be positively related to the attitude towards EBP (Figure 1). The positive attitude towards learning communicative competences has been assumed to play an intermediate role. This assumption is based on the observations made by Wittenberg et al. (2017) [12], who indicated that an adequate level of communication skills determines the correct and effective provision of spiritual nursing care. This applies in particular to nonverbal communication, listening, and discussing patients' emotions. Concerning the above, the nurses who want to provide spiritual care effectively tend to aware of the need to improve their communication skills, which can translate onto a positive attitude towards learning communicative competences. A positive attitude towards learning communicative competences should, in turn, lead to a positive attitude towards EBP, which is suggested, e.g., in the studies conducted by Adams et al. (2017) [11], Allenbaugh et al. (2019) [14]. The age of the nurse can also be of key significance in the proposed model. The available test results do not allow for stating clearly the extent to which the age or job seniority can condition a positive attitude towards EBP or learning communicative competences [15]. 


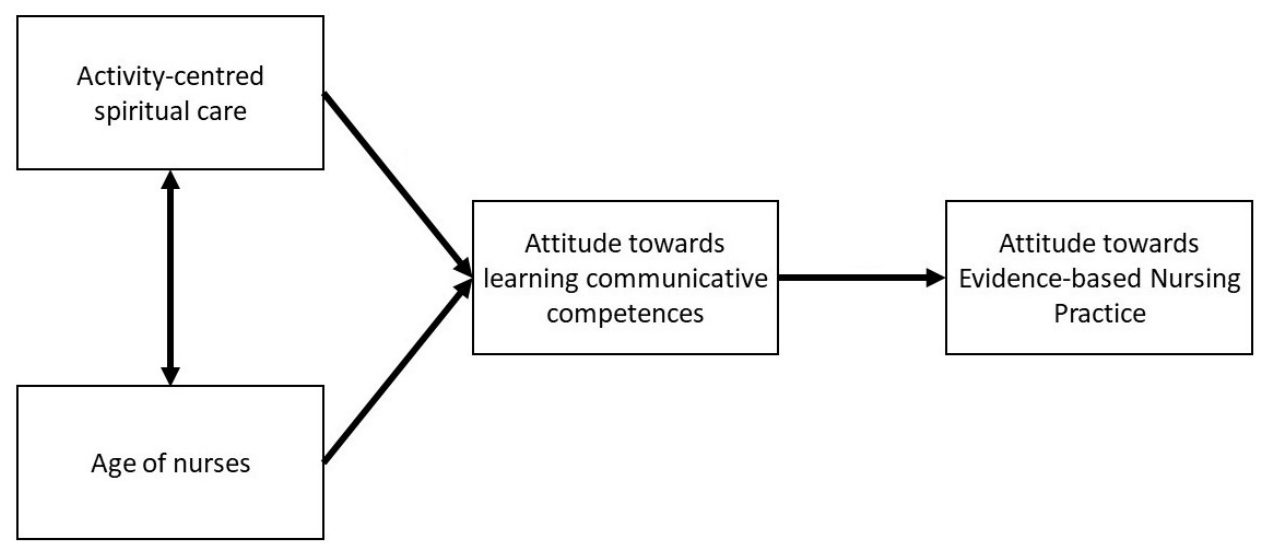

Figure 1. The theoretical model of the relationship between the tested variables.

\subsection{Aim}

To assess the perception of spirituality and the nurse's role in providing spiritual care, as well as the perception of the significance of communication skills in the approval of EBP in the professional practice.

\section{Methods}

\subsection{Design}

A multi-centre cross-sectional national study was conducted in Poland from February to June 2019.

\subsection{Sample and Setting}

Ten Polish medical universities educating students in first-cycle (corresponding to the 6th Level of the European Qualifications Framework) and second-cycle studies (corresponding to the 7th Level of the European Qualifications Framework) of a nursing major were invited to participate in the study. These universities educate $30 \%$ and $50 \%$ of all Polish students undertaking a major in nursing in both cycles of study, respectively.

The study population consisted of two subgroups: 459 undergraduate (Bachelor programme, BP) and 717 postgraduate students (Master programme, MP). For the BP group, being a student in the last (third) year of studies was the inclusion criterion. For the MP group, being a first- or second-year student and declaring at least three years of professional experience were the inclusion criteria.

A total of 1475 students were qualified for the study, and necessary data were obtained from 1,176 of them (response rate 79.7\%). With this sample size and the number of nursing students in Poland ( $\mathrm{N}=9000)$, the error margin was $2.72 \%$ ( $95 \%$ confidence level).

\subsection{Ethical Considerations}

Before taking part in the study, voluntary informed consent to participate was obtained from each participant. The aim of the study, as well as the methods of analysis and data storage, was explained to the participants in writing. The participants were also informed that confidential data would be used for scientific purposes only. The Local Personal Data Inspector raised no contraindications regarding the data protection of the study participants.

\subsection{Variables}

We used the Evidence-Based Practice Competence Questionnaire (EBP-COQ) created by Ruzafa-Martinez et al. (2013) [16], in the form of the Polish adaptation constructed by Panczyk et al. (2020) [17]. The questionnaire consists of 25 items arranged into three subscales: attitude toward EBP, skills in EBP, knowledge in EBP. As this publication is 
focused on the fundamentals, the authors only used the scale referring to the attitude towards EBP.

The Spirituality and Spiritual Care Rating Scale (SSCRS) developed by McSherry et al. (2002) [18] is used for the measurement of spirituality and spiritual care in nursing. The scale consists of 17 items, with subscales emotional support-centred spiritual care, ACSC, and religiosity. The authors of the paper analysed only the ACSC subscale.

The Communication Skills Attitude Scale (CSAS) constructed by Rees et al. (2002) [19] (Polish adaptation by Panczyk et al. (2019) [20]) was used for the measurement of attitudes towards learning communicative competences. The validated Polish version contains 23 statements pertaining to the attitude towards learning communicative competences in both teaching the profession and in professional practice. The scale is divided into two subscales: a positive one and a negative one. The final CSAS result was used in the study.

Some sociodemographic data of the study group were collected, including the nursing school, age, and job seniority, as well as previous participation in training for EBP, communication skills or spiritual care.

\subsection{Data Collection}

The data were collected by means of an auditorium survey. Students sitting in one room after their class were asked to fill in the questionnaire. The trained interviewers communicated the purpose of the study orally and informed the participants of how to fill in the questionnaires. The interviewers were also responsible for collecting the filledin questionnaires and securing them before they were sent to the central unit coordinating the study.

\subsection{Data Analysis}

Descriptive statistics methods (means and standard deviations) and structure indicators (numbers and frequencies) were used for the analysis of the variables collected in the study. In order to compare the two study groups (BP vs. MP) regarding the relevant characteristics, a chi-square independence test or Student's t-test was used, depending on the type of the variable. The calculations were performed using the STATISTICA package, version 13.3 (Tibco Software Inc., Palo Alto, CA, United States). A 0.05 significance level was set.

All analyses were carried out using the structural equation modelling program Mplus version 7.0 [21]. We used two-group structural equation modelling: BP vs. MP. The purpose of the analysis was to obtain an answer to the question of whether the collected empirical data confirm the relationship between the variables that was assumed by the researchers. To that end, the model's parameters were estimated (path coefficients, variance and covariance) and these were used for building a theoretical variance-covariance matrix of the variables employed in the model (Figure 2). We checked whether the calculated model's parameters varied for BP vs. MP. Maximum likelihood estimation with robust standard errors was used to calculate the structural model's parameters. 


$$
\left\{\begin{array}{l}
E B P=\gamma_{11}{ }^{B P}(C S A S)^{B P}+e_{1}{ }^{B P} \\
C S A S=\gamma_{21}{ }^{B P}(A g e)^{B P}+\gamma_{23}{ }^{B P}(A C S C)^{B P}+e_{2}{ }^{B P} \\
\operatorname{Cov}(\text { Age }, A C S C)^{B P}=\varphi_{12}{ }^{B P} \\
E B P=\gamma_{11}{ }^{M P}(C S A S)^{M P}+e_{1}^{M P} \\
C S A S=\gamma_{21}{ }^{M P}(\text { Age })^{M P}+\gamma_{23}{ }^{M P}(\text { ACSC })^{M P}+e_{2}^{M P} \\
\operatorname{Cov}(\text { Age }, A C S C)^{M P}=\varphi_{12}{ }^{M P}
\end{array}\right.
$$

Figure 3. The formal form of the structural equation model. BP-Bachelor programme, MP-Master programme, EBP - attitude towards evidence-based nursing practice, CSAS-attitude towards learning communicative competences, ACSC-Activity-Centred Spiritual Care.

The fit of the model was assessed using the following statistics and indices: the chisquare test of model fit (CMIN), normal chi-square (CMIN/DF), the Comparative Fit Index (CFI), the Tucker-Lewis Index (TLI), the Root Mean Square Error of Approximation (RMSEA), and Standardised Root Mean Square Residual (SRMR). In the evaluation of the model, the chi-square statistics were expected to be insignificant. The recommended values of indices were as follows: $\chi 2$ divided by the degrees of freedom $(\mathrm{CMIN} / \mathrm{DF}) \leq 3.00$; RMSEA < 0.080 and SRMR < 0.050; CFI and TLI > 0.95 [22].

\section{Results}

\subsection{Participant Characteristics}

Both groups of study participants varied in a statistically significant way by the mean age (BP vs. MP: 23.1 (3.79) vs. 32.6 (10.91); $t=17.861, p<0.001)$. Regarding the selected characteristics, the groups varied significantly for such aspects as nursing school, place of residence, and spiritual care training. Table 1 reports a comparison of the selected demographic characteristics of the participants who completed this study. 
Table 1. Participant characteristics.

\begin{tabular}{|c|c|c|c|c|c|c|c|c|}
\hline & \multicolumn{2}{|c|}{$\begin{array}{c}\text { Total } \\
(\mathrm{N}=1176)\end{array}$} & \multicolumn{2}{|c|}{$\begin{array}{c}\text { Bachelor Pro- } \\
\text { gramme } \\
(\mathrm{N}=459)\end{array}$} & \multicolumn{2}{|c|}{$\begin{array}{c}\text { Master Pro- } \\
\text { gramme } \\
(\mathrm{N}=717)\end{array}$} & \multirow[t]{2}{*}{$\chi^{2}$} & \multirow[t]{2}{*}{$p$-Value * } \\
\hline & $\mathbf{N}$ & $\%$ & $\mathbf{N}$ & $\%$ & $\mathbf{N}$ & $\%$ & & \\
\hline \multicolumn{9}{|l|}{ Nursing School } \\
\hline Medical University of Bialystok & 162 & 13.8 & 16 & 3.4 & 147 & 20.5 & \multirow{7}{*}{158.4} & \multirow{7}{*}{$<0.001$} \\
\hline Medical University of Lublin & 141 & 12.0 & 83 & 18.1 & 58 & 8.1 & & \\
\hline Jagiellonian University Medical College & 211 & 17.9 & 92 & 20.1 & 118 & 16.5 & & \\
\hline Poznan University of Medical Sciences & 171 & 14.5 & 70 & 15.2 & 101 & 14.1 & & \\
\hline Medical University of Lodz & 194 & 16.5 & 112 & 24.4 & 82 & 11.4 & & \\
\hline Medical University of Silesia & 79 & 6.7 & 0 & 0.0 & 79 & 11.0 & & \\
\hline Medical University of Warsaw & 219 & 18.6 & 87 & 18.9 & 132 & 18.4 & & \\
\hline \multicolumn{7}{|l|}{ Gender } & \multirow{3}{*}{2.163} & \multirow{3}{*}{0.141} \\
\hline Female & 1104 & 93.9 & 425 & 92.6 & 679 & 94.7 & & \\
\hline Male & 72 & 6.1 & 34 & 7.4 & 38 & 5.3 & & \\
\hline \multicolumn{9}{|l|}{ Place of residence } \\
\hline Countryside & 309 & 26.3 & 190 & 41.3 & 119 & 16.7 & \multirow{5}{*}{100.4} & \multirow{5}{*}{$<0.001$} \\
\hline Village (population up to 50 thousand) & 180 & 15.3 & 64 & 14.0 & 116 & 16.1 & & \\
\hline $\begin{array}{l}\text { Small town (51-200 thousand inhabit- } \\
\text { ants) }\end{array}$ & 144 & 12.3 & 33 & 7.2 & 111 & 15.5 & & \\
\hline $\begin{array}{l}\text { Large town (201-500 thousand inhabit- } \\
\text { ants) }\end{array}$ & 190 & 16.2 & 47 & 10.3 & 143 & 19.9 & & \\
\hline City $>500$ thousand inhabitants & 353 & 30.0 & 125 & 27.2 & 228 & 31.8 & & \\
\hline \multicolumn{9}{|l|}{ Spiritual care training } \\
\hline No & 365 & 31.1 & 168 & 36.7 & 197 & 27.5 & \multirow{2}{*}{10.888} & \multirow{2}{*}{0.001} \\
\hline Yes & 811 & 68.9 & 291 & 63.3 & 520 & 72.5 & & \\
\hline \multicolumn{9}{|l|}{ EBP training } \\
\hline No & 1105 & 94.0 & 431 & 94.0 & 674 & 94.0 & \multirow{2}{*}{0.005} & \multirow{2}{*}{0.942} \\
\hline Yes & 71 & 6.0 & 28 & 6.0 & 43 & 6.0 & & \\
\hline \multicolumn{9}{|l|}{ Communication skills training } \\
\hline No & 960 & 81.6 & 374 & 81.4 & 586 & 81.7 & \multirow{2}{*}{0.012} & \multirow{2}{*}{0.915} \\
\hline Yes & 216 & 18.4 & 85 & 18.6 & 131 & 18.3 & & \\
\hline
\end{tabular}

${ }^{*}$ Chi-squared test

\subsection{Variables}

Skewness and kurtosis were evaluated for all the analysed data, which revealed a left-sided asymmetry and a lack of compliance with a normal distribution. The deviations in compliance with normal distribution were not very high because the skewness and kurtosis, which ranged from -1.5 to +1.5 .

We also analysed whether the two study groups varied significantly with regard to the tested features. The mean intensity of the characteristics was observed to be lower in a statistically significant way in the BP than the MP group. The effect sizes were not similar between these variables. The details of the results are summarised in Table 2. 
Table 2. Comparison of two study groups in terms of variables.

\begin{tabular}{|c|c|c|c|c|c|c|c|}
\hline \multirow{2}{*}{ Variable } & \multicolumn{2}{|c|}{ Bachelor Programme } & \multicolumn{2}{|c|}{ Master Programme } & \multirow{2}{*}{$t_{(\mathrm{df}=1174)}$} & \multirow{2}{*}{$p$-Value * } & \multirow{2}{*}{$\begin{array}{c}D^{* *} \\
(95 \% \mathrm{CI}) \\
\end{array}$} \\
\hline & M & SD & $\mathbf{M}$ & SD & & & \\
\hline $\begin{array}{c}\text { Attitude Towards Evidence- } \\
\text { Based Nursing Practice }\end{array}$ & 47.65 & 7.22 & 49.34 & 7.28 & 3.891 & $<0.001$ & $\begin{array}{c}0.23 \\
(0.12 ; 0.35) \\
\end{array}$ \\
\hline $\begin{array}{l}\text { Attitude Towards Learning } \\
\text { Communicative Competences }\end{array}$ & 83.61 & 13.03 & 87.48 & 12.67 & 5.050 & $<0.001$ & $\begin{array}{c}0.30 \\
(0.18 ; 0.42) \\
\end{array}$ \\
\hline Activity-Centred Spiritual Care & 33.71 & 9.15 & 34.79 & 8.47 & 2.064 & 0.039 & $\begin{array}{c}0.12 \\
(0.01 ; 0.24)\end{array}$ \\
\hline
\end{tabular}

$\mathrm{M}-$ mean, SD-standard deviation, CI-confidence interval. * Student's $t$-test. ${ }^{*}$ Cohen's $d$ coefficient.

\subsection{Measurement Model}

Both calculated values $(\mathrm{CMIN}=1.797, \mathrm{df}=4$ and $\mathrm{CMIN} / \mathrm{DF}=0.45)$ indicate that the assumed theoretical model is confirmed by the empirical data. The CMIN contribution from each group amounted to $0.529(\mathrm{CMIN} / \mathrm{DF}=0.12)$ for $\mathrm{BP}$ and $1.268(\mathrm{CMIN} / \mathrm{DF}=0.32)$ for MP. Moreover, based on the obtained value of the test probability $(p=0.773)$, the hypothesis regarding the lack of difference between the theoretical and empirical variancecovariance matrixes was highly likely correct. The results of the test invariance across groups indicate that the model varies in a statistically significant way between the two study groups $(\mathrm{CMIN}=10.863, \mathrm{df}=3, p=0.012)$ for the path parameters.

The value of the divergence function F0 and the value of the RMSEA index corrected by the number of the degrees of freedom were determined. The value of RMSEA (0.001, $90 \% \mathrm{CI}(0.000 ; 0.042), p=0.975)$ suggests that both matrices are equal. The value of SRMR was below the assumed threshold and amounted to 0.009 . The results confirm a good fit of the data to the assumed structure of the model.

In order to more accurately estimate the degree of model fit to the collected data, the fit indices were determined, and we compared the tested model with the depended model (the model in which the variables are not correlated). The CFI value (0.999) and its corrected value, i.e., TLI (1.000), were estimated. The results suggest that the tested model explains nearly $100 \%$ of the variable variance.

\subsection{Associations Between Variables}

An analysis of the proposed path model revealed that all relations had a positive effect. The CSAS variable was observed to have a significant direct effect on the explained variable (EBP). For this relation in the BP and MP groups, the values of the standardised regression weights amounted to $0.327(p<0.001)$ and $0.332(p<0.001)$, respectively. The observed relationship did not vary in a statistically significant way between BP and MP $(\mathrm{CMIN}=0.086, \mathrm{df}=1, p=0.769)$.

The effects of the two variables (Age and ACSC) on CSAS were different in the two compared groups. Although in the BP group, the ACSC variable exerted a fairly strong effect on CSAS, in the MP group, the relationship was significantly weaker. The values of the standardised regression weights amounted to $0.347(p<0.001)$ and $0.160(p<0.001)$, respectively, and the difference between $\mathrm{BP}$ and MP was statistically significant (CMIN = 9.643, $\mathrm{df}=1, p=0.002)$. In reference to the effect of age, it was observed that in the BP group, the variable did not affect CSAS in a significant way $(0.037, p=0.398)$, whereas such an influence was observed in the MP group $(0.255, p<0.001)$.

As far as the correlation between Age and ACSC is concerned, no statistically significant relationship was observed in either the BP or the MP group ( $p$-value 0.834 and 0.057 , respectively). The details of the parameter estimation used for a model of structural equations, including a comparative analysis of the groups, are shown in Table 3. 
Table 3. Standardised regression weights and test invariance across groups.

\begin{tabular}{cccccccccccc}
\hline \multirow{2}{*}{ Construct } & \multicolumn{4}{c}{ Bachelor Programme } & \multicolumn{4}{c}{ Master Programme } & \multirow{2}{*}{ CMIN } & \multirow{2}{*}{$\boldsymbol{p}$-Value } \\
\cline { 2 - 11 } & Estimate & SE & CR & $\boldsymbol{p}$-Value Estimate & SE & CR & $\boldsymbol{p}$-Value & & \\
\hline CSAS --> EBP & 0.327 & 0.042 & 7.85 & 0.000 & 0.332 & 0.033 & 9.98 & 0.000 & 0.086 & 0.769 \\
Age --> CSAS & 0.037 & 0.044 & 0.84 & 0.398 & 0.255 & 0.03 & 7.41 & 0.000 & 1.177 & 0.278 \\
ACSC --> CSAS & 0.347 & 0.041 & 8.47 & 0.000 & 0.160 & 0.035 & 4.56 & 0.000 & 9.643 & 0.002 \\
Age <-> ACSC & -0.01 & 0.047 & -0.21 & 0.834 & 0.071 & 0.037 & 1.91 & 0.057 & 3.260 & 0.071 \\
\hline
\end{tabular}

SE - standard error, $\mathrm{CR}$ - critical ratio, EBP - attitude towards evidence-based nursing practice, CSAS-attitude towards learning communicative competences, ACSC-Activity-Centred Spiritual Care test invariance across groups.

By analysing the model and the direct effects, we determined the value of indirect effects (where the effect of the explaining variables on the explained variable is not direct). The first of the indirect effects in the presented model was executed according to the ACSC --> CSAS --> EBP path (standardised regression weight in BP and MP group: 0.113 and 0.053 , respectively). This indirect effect was much weaker in the BP than in the MP group. The other indirect effect was executed via the Age --> CSAS --> EBP path (standardised regression weight in the BP and MP group: 0.012 and 0.085 , respectively). This indirect effect was thus much weaker in the BP group. The details of the parameter estimation for a model of structural equations, with all direct and indirect effects, are shown in Figure 3.

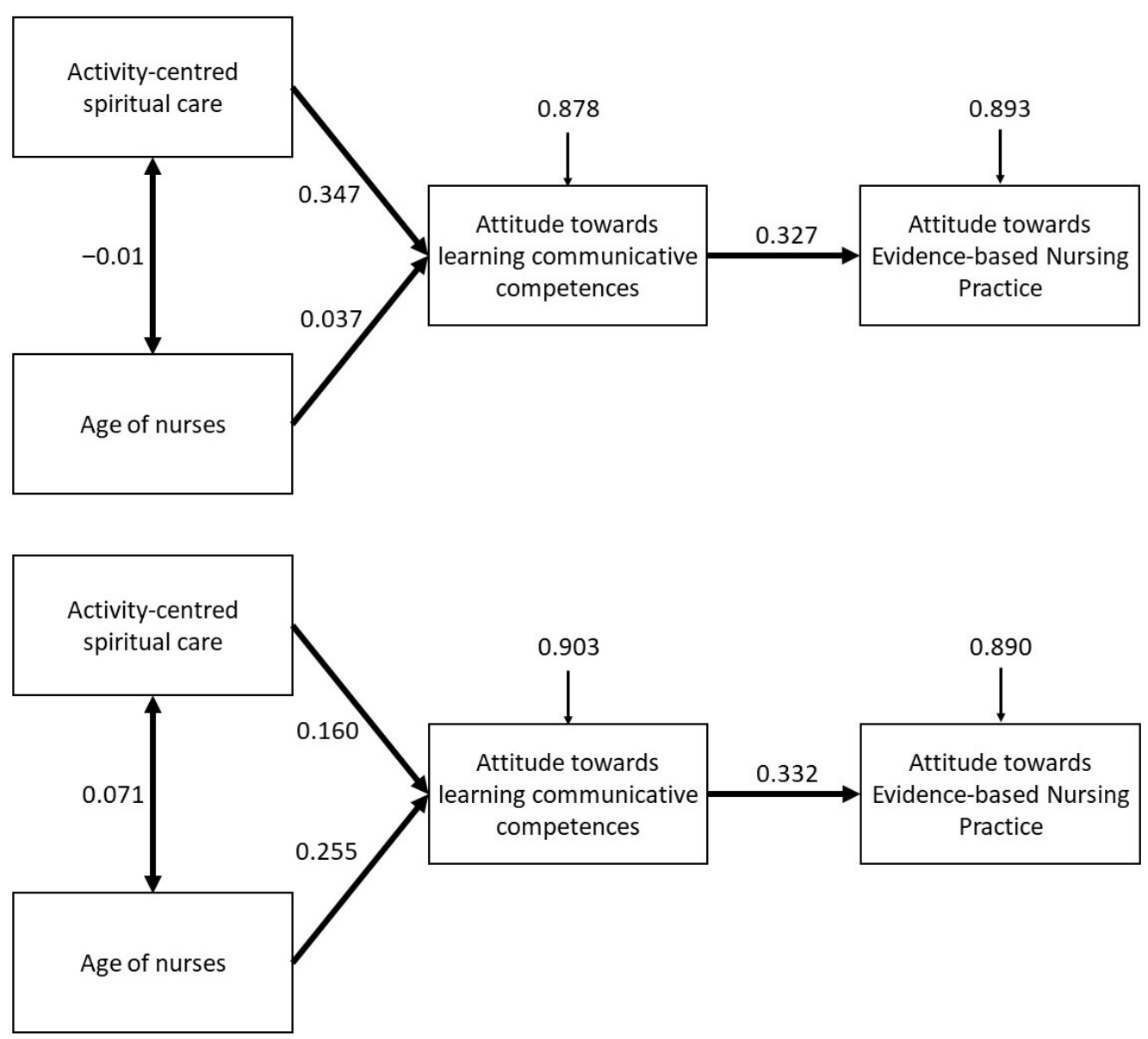

Figure 3. Pathway diagram for BP group (above) and MP group (below). Correlations between independent variables are represented with a double-sided arrow. Direct effects are represented with a one-sided arrow. The numbers above the arrow indicate the value of standardised regression weights. The numbers before the arrow show residual variances. 


\section{Discussion}

The role of the attitude towards learning communicative competences, as a bridge between the perception of spiritual care and the approval of EBP, was analysed based on a previously developed theoretical model, which was verified empirically. The theoretically assumed relationships between the analysed variables (attitude towards learning communicative competences, ACSC, attitude towards EBP) were confirmed by the tested model in two groups: BP and MP. Given that nursing practice is based on team collaboration, the comparison of the groups was based on the assumptions of management theories, which emphasise the role of age diversity and experience in the development of a friendly working environment $[23,24]$.

In the context of the contemporary management of nursing staff, a positive attitude towards learning communication skills as well as proceeding according to EBP both play an important role, which is a real challenge in everyday clinical practice. This may be related to the existence of different educational paths in the area of EBP, or the lack of such paths in the curricula, as well as several constraints that hamper the implementation of EBP in organisations [4]. Nowadays, two different approaches to nursing practice may be employed in one team - one based on scientific evidence, and one based on personal convictions and intuition resulting from experience $[25,26]$. The two different attitudes may affect the nurses' approach to learning communication skills and using them in nursing care. By observing the behaviour of other people in their environment, a nurse can follow a behavioural pattern as a result of behaviour modelling. This is of particular importance in reference to nurses starting their professional career right after graduation. Their idealistic approach can be modified when they face the reality of clinical practice and observe the behaviours of their colleagues $[27,28]$.

The collected data reveal that the nurse's age and related life experience affect their attitude towards the variables studied in the developed model. The age of nurses was directly positively correlated with the attitude towards learning communicative competences, and was indirectly related to the attitude towards EBP. Hence the attitude towards learning communicative competences can depend on whether the person has already started their career or is still learning, supervised by a teacher under simulated conditions, which are often idealised as compared to the reality of working in hospital wards. These deliberations can be confirmed by personal job experience and discussions with experienced nurses, as well as with persons who have just graduated from their own nursing studies. These observations reveal that not all graduates or active nurses are satisfied with the level of their communication skills, and more importantly, they express the need to strengthen them. A similar opinion can be found in studies on nurses' soft skills [29], studies devoted to patients' needs [14] and the theoretical model of the nursing theory developed by Watson and Smith [8].

Watson emphasises that communication skills should be highly developed due to the specificity of a nurse's job [8]. The model proposed in the study strongly corresponds with Watson's humanistic theory, which places human needs in the central position. The patient's needs can be satisfied by building a therapeutic bond, which requires adequate communication skills from the nursing staff [30]. Furthermore, adequate communication skills are considered to contribute directly to the reduction in medical errors and the increase in patient safety, as well as to making the care plan better and more efficient, which means shorter hospitalisation time for the patient [24]. This is also reflected in the developed model, wherein regardless of the study group (BP or MP), the attitude towards learning communicative competences is positively correlated with all the variables. Studies by Mattson et al. (2015) [24] and Kirca and Bademli (2019) [29] have revealed that the development of communication skills brings several benefits - both for the staff's development and for competence strengthening - as they contribute to professional adaptation and reduce the risk of burnout.

Another important aspect of the study that differentiates the two analysed groups is the perception of spiritual care. The developed model suggests that professional 
experience can affect the perception of the nurse's role in providing spiritual care, which is among the most essential areas of nursing care, and is based both on adequate communication skills [8] and a specific mental disposition (e.g., empathy) and self-awareness. Physical confrontation with the patient's spiritual needs requires specific measures to be taken by the nurse, which should comply with the adopted standards and EBP. This, in turn, increases self-awareness in advancing one's skills in the area of spiritual care according to the EBP concept, which includes the patient's expectations, preferences and individual needs. In other words, professional experience can modify the idealised perception of one's own skills in providing spiritual care, and a shift from "intuitive proceeding" to more evidence-based proceeding. In spiritual care, it is crucial to understand another person's situation without judging them, and remaining open to support them in times of hardship. It thus means referring to facts rather than to one's emotions or convictions.

The presented model demonstrates an indirect relationship between the perception of ACSC and the attitude towards EBP. The attitude towards learning communicative competences is the bridge between the variables. It can be assumed that a positive approach to learning communication skills affects a nurse's self-assessment and his/her sense of being capable of entering into difficult discussions with the patient, as well as with members of the nursing team or other health care professionals [31]. Hence communication skills and spiritual care are strongly related to EBP, because each of them strive towards the patient's conscious participation in the therapeutic process. In this context, the nurse's approach to the integrated (simultaneous) learning of competences is essential.

The developed model not only indicates the possibility of integrating a humanistic approach with EBP, but it also enables the conscious and insightful influence of different groups of recipients: nurses, managers of the health care system or of the nursing staff, academic teachers, and nursing students.

Knowledge of the relationships between the attitude towards learning communicative competences, ACSC, and the attitude towards EBP can help nurses to make more conscious decisions regarding undertaking postgraduate education. It applies both to education and self-improvement, which takes into consideration the balance between hard and soft competencies. It can significantly strengthen one's sense of self-confidence in making independent decisions based on EBP, by incorporating a humanistic aspect into the nursing practice. The approach presented in the model will help to improve the quality of care, reduce the risk of burnout, and enable easier adaptation to the working environment.

Academic teachers can take advantage of the observations resulting from the model for the better execution of practical classes based on EBP, and for developing a curriculum covering the simultaneous teaching of hard and soft competencies. It will help improve teaching effectiveness. Consequently, staff with an adequate scope of competences will be able to provide the highest level of care [32].

It should be emphasised that the developed empirical model integrates EBP with a humanistic approach, encouraging the perception of communication skills as a stable and robust bridge between the two areas. To a certain extent, the model varies depending on whether it applies to working professionals or students, but the pillars of the concept remain the same. Only the emphasis is shifted between the pillars. The presented model highlights the importance of self-awareness and self-diagnosis of one's strengths and weaknesses. This fits the current concept of nurses' professional independence.

\section{Study Limitations}

The interpretation of the results is subjected to some constraints that must be taken into consideration when evaluating the results. First and foremost, working nurses who decided to undertake postgraduate studies were included in the study. Consequently, this group may be more aware of the need to improve their skills. The study did not include working nurses who did not continue their postgraduate education. Declarative participation in different types of training (e.g., spiritual care training, EBP training and 
communication skills training) was controlled in the study, without our having learnt the thematic scope of the training. The model was developed based on data from a crosssectional study.

\section{Conclusion}

The developed empirical model integrates the concept of EBP with the humanistic component of emphasising the patient's needs, which should become the centre of the nurse's attention. The practical execution of this kind of nursing care requires well-developed communicative competences, which create a stable bridge linking the two different approaches. The relations comprising the present model include not only a holistic approach to nursing care, but also guidelines regarding practical actions that can enable conscious and insightful educational actions (e.g., among students, nurses and academic teachers).

Author Contributions: L.I., investigation, original draft preparation. S.M., data curation. M.J., conceptualisation, validation, original draft preparation, and supervision. D.W., data curation. J.G., supervision. M.P., conceptualisation, methodology, software, and writing-reviewing and editing.

Funding: The study was conducted with the financial support of a research grant from the Medical University of Warsaw (PW/Z/10/5//20(1)).

Institutional Review Board Statement: The study was conducted according to the guidelines of the Declaration of Helsinki, and approved by the Ethics Committee of Warsaw Medical University (IRB approval no. AKBE/37/2019 February 18, 2019).

Informed Consent Statement: Informed consent was obtained from all subjects involved in the study.

Data Availability Statement: The data that support the findings of this study are available on request from the corresponding author [M.P.].

Conflicts of Interest: The authors declare no potential conflicts of interest with respect to the research, authorship, and/or publication of this article.

Acknowledgments: We would like to thank Kamila Kraszewska for her help in digitising the survey data. We would like to thank all students who participated in the study.

\section{References}

1. International Council of Nurses. Closing the Gap: from Evidence to Action. 2012 Available online: https://www.nursingworld.org/ 4aff6a/globalassets/practiceandpolicy/innovation--evidence/ind-kit-2012-for-nnas.pdf (accessed on 20.10.2021).

2. Canadian Nurses Association. Evidence-based Decision-Making and Nursing Practice. Availabe online: https://www.nurseone.ca/ /media/nurseone/page-content/pdf-en/ps63_evidence_based_decision_making_nursing_practice_e.pdf?la=en (accessed on 20.10.2021).

3. Belowska, J.; Panczyk, M.; Zarzeka, A.; Iwanow, L.; Cieslak, I.; Gotlib, J. Promoting evidence-based practice - perceived knowledge, behaviours and attitudes of Polish nurses: a cross-sectional validation study. Int. J. Occup. Saf. Ergon. 2020, 26, 397405, doi:10.1080/10803548.2018.1489993.

4. Sadeghi-Bazargani, H.; Tabrizi, J.S.; Azami-Aghdash, S. Barriers to evidence-based medicine: a systematic review. J. Eval. Clin. Pr. 2014, 20, 793-802, doi:10.1111/jep.12222.

5. Hertog, R.D.; Niessen, T. The role of patient preferences in nursing decision-making in evidence-based practice: excellent nurses' communication tools. J. Adv. Nurs. 2019, 75, 1987-1995, doi:10.1111/jan.14083.

6. Straus, S.; Glasziou, P.; Richardson, W.; Haynes, R. Evidence-Based Medicine E-Book: How to Practice and Teach EBM; Elsevier Health Sciences: New York, NY, USA, 2018.

7. Henderson, V. The concept of nursing. J. Adv. Nurs. 1978, 3, 113-130, doi:10.1111/j.1365-2648.1978.tb00837.x.

8. Watson, J.; Smith, M.C. Caring science and the science of unitary human beings: a trans-theoretical discourse for nursing knowledge development. J. Adv. Nurs. 2002, 37, 452-461, doi:10.1046/j.1365-2648.2002.02112.x. 
9. D'Antonio, P.; Beeber, L.; Sills, G.; Naegle, M. The future in the past: Hildegard Peplau and interpersonal relations in nursing. Nurs. Inq. 2014, 21, 311-317, doi:10.1111/nin.12056.

10. Petty, R.E.; Wegener, D.T.; Fabrigar, L.R. Attitudes and attitude change. Annu. Rev. Psychol. 1997, 48, 609-647, doi:10.1146/annurev.psych.48.1.609.

11. Adams, A.; Mannix, T.; Harrington, A. Nurses' communication with families in the intensive care unit - a literature review. Nurs. Crit. Care 2017, 22, 70-80, doi:10.1111/nicc.12141.

12. Wittenberg, E.; Ragan, S.L.; Ferrell, B. Exploring Nurse Communication About Spirituality. Am. J. Hosp. Palliat. Med. 2017, 34, 566-571, doi:10.1177/1049909116641630.

13. Alotaibi, F.S.; Alsaeedi, A. Attitudes of medical students toward communication skills learning in Western Saudi Arabia. Saudi Med. J. 2016, 37, 791-795, doi:10.15537/smj.2016.7.14331.

14. Allenbaugh, J.; Corbelli, J.; Rack, L.; Rubio, D.; Spagnoletti, C. A Brief Communication Curriculum Improves Resident and Nurse Communication Skills and Patient Satisfaction. J. Gen. Intern. Med. 2019, 34, 1167-1173, doi:10.1007/s11606-019-04951-6.

15. Al-Kalaldeh, M.; Amro, N.; Qtait, M.; Alwawi, A. Barriers to effective nurse-patient communication in the emergency department. Emerg. Nurse 2020, 28, 29-35, doi:10.7748/en.2020.e1969.

16. Ruzafa-Martinez, M.; Lopez-Iborra, L.; Moreno-Casbas, T.; Madrigal-Torres, M. Development and validation of the competence in evidence based practice questionnaire (EBP-COQ) among nursing students. BMC Med. Educ. 2013, 13, 19, doi:10.1186/14726920-13-19.

17. Panczyk, M.; Iwanow, L.; Gaworska-Krzemińska, A.; Grochans, E.; Kózka, M.; Kulik, H.; Lewko, J.; Marcysiak, M.; Młynarska, K.; Nowak-Starz, G., et al. Validation study and setting norms of the evidence based practice competence questionnaire for nursing students: A cross-sectional study in Poland. Nurse Educ. Today 2020, 88, 104383, doi:10.1016/j.nedt.2020.104383.

18. McSherry, W.; Draper, P.; Kendrick, D. The construct validity of a rating scale designed to assess spirituality and spiritual care. Int. J. Nurs. Stud. 2002, 39, 723-734, doi:10.1016/s0020-7489(02)00014-7.

19. Rees, C.; Sheard, C.; Davies, S. The development of a scale to measure medical students' attitudes towards communication skills learning: the Communication Skills Attitude Scale (CSAS). Med. Educ. 2002, 36, 141-147.

20. Panczyk, M.; Iwanow, L.; Zarzeka, A.; Jaworski, M.; Gotlib, J. Communication skills attitude scale: a translation and validation study in asample of registered nurses in Poland. BMJ Open 2019, 9, e028691, doi:10.1136/ bmjopen-2018-028691.

21. Muthén, L.; Muthén, B. The Comprehensive Modelling Program for Applied Researchers: User's Guide, 5; Los Angeles, CA, USA, 2016.

22. Hooper, D.; Coughlan, J.; Mullen, M. Structural Equation Modelling: Guidelines for Determining Model Fit; University Press of America: New York, NY, USA, 1993.

23. Kuthy, J.E.; Ramon, C.; Gonzalez, R.; Biddle, D.A. Practical implications of pre-employment nurse assessments. Health Care Manag. 2013, 32, 189-192, doi:10.1097/hcm.0b013e31828ef687.

24. Mattson, M.; Hellgren, J.; Goransson, S. Leader communication approaches and patient safety: An integrated model. J. Saf. Res. 2015, 53, 53-62, doi:10.1016/j.jsr.2015.03.008.

25. Duncombe, D.C. A multi-institutional study of the perceived barriers and facilitators to implementing evidence-based practice. J. Clin. Nurs. 2018, 27, 1216-1226, doi:10.1111/jocn.14168.

26. Li, S.; Cao, M.; Zhu, X. Evidence-based practice: Knowledge, attitudes, implementation, facilitators, and barriers among community nurses-systematic review. Medicine 2019, 98, e17209, doi:10.1097/md.0000000000017209.

27. Yang, J.; Matz-Costa, C. Age Diversity in the Workplace: The Effect of Relational Age Within Supervisor-Employee Dyads on Employees' Work Engagement. Int. J. Aging Hum. Dev. 2018, 87, 156-183, doi:10.1177/0091415017709798.

28. Zacher, H.; Rudolph, C.W. Successful Aging at Work and Beyond: A Review and Critical Perspective; Emerald Publishing Limited: Bingley, UK, 2017; pp. 35-64.

29. Kirca, N.; Bademli, K. Relationship between communication skills and care behaviors of nurses. Perspect. Psychiatr. Care 2019, 55, 624-631, doi:10.1111/ppc.12381. 
30. Yardley, S.J.; Walshe, C.E.; Parr, A. Improving training in spiritual care: a qualitative study exploring patient perceptions of professional educational requirements. Palliat. Med. 2009, 23, 601-607, doi:10.1177/0269216309105726.

31. Onan, N.; Ünsal Barlas, G.; Karaca, S.; Kocaman Yıldırım, N.; Taşkıran, Ö.; Sümeli, F. The relations between perceived stress, communication skills and psychological symptoms in oncology nurses. Journal of Marmara University Institute of Health Sciences. 2015, 5, 170-177, doi: 10.5455/musbed.20150602021515.

32. Fineout-Overholt, E.; Baldwin, C.M.; Greenberg, E.A. Evidence-based practice in the holistic nursing process. Begin. CNE 2005, $25,13$. 